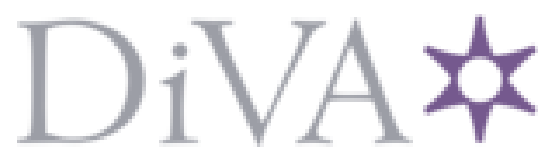

http://www.diva-portal.org

This is the published version of a paper presented at 13th International Conference on Probabilistic Methods Applied to Power Systems, Durham, 7-10 July 2014.

Citation for the original published paper:

Ekstedt, N., Hilber, P. (2014)

Categorization and Review of Failure Rate Factors Used in Power Systems.

In:

N.B. When citing this work, cite the original published paper.

Permanent link to this version:

http://urn.kb.se/resolve?urn=urn:nbn:se:kth:diva-154069 


\title{
Categorization and Review of Failure Rate Factors Used in Power Systems
}

\author{
Niklas Ekstedt and Patrik Hilber \\ School of Electrical Engineering \\ KTH - Royal Institute of Technology \\ Stockholm, Sweden \\ niklas.ekstedt@ee.kth.se and hilber@kth.se
}

\begin{abstract}
To evaluate the reliability of power systems, good estimates of the failure rates of the included components are needed. Better predictions can be performed if relevant factors that affect the failure rates are used, and an increasing number of models that include different types of factors have been presented recently. This paper proposes a categorization of failure rate factors into seven categories, based on the type of information for the factors. The categorization can be used to map future studies in the context of similar work. Furthermore, the paper presents a review of a number of publications that uses different factors to model the failure rate of different power system components. The failure rate factors used in the reviewed publications are categorized into the proposed seven categories and a comprehensive summary table is included. The used models and methods to estimate the failure rate in the reviewed publications are also noted in the summary table.
\end{abstract}

Keywords-failure analysis; failure rate; failure rate factors; failure statistics; power system reliability

\section{INTRODUCTION}

A reliable power supply is crucial for the modern society, and better knowledge about the unpredicted events that disturb the supply is therefore desirable. Industries, infrastructure, and citizens are counting on and are demanding power when needed, and outages can be disastrous for the affected parties. The importance creates a need of better and more precise reliability predictions, and progress in the science and better software programs enables the usage of more explaining factors in the reliability models. One of the key concepts of probabilistic methods applied to power systems is the usage of a failure rate, instead of a deterministic view of component failures, and many are the reliability models and methods that use the failure rate of components as an input parameter. However, the methods can be sensible of the accuracy of the failure rate estimate. To accurately describe the failure rate of a component, as much information as possible should be utilized, and it is therefore important to know which factors that can be used for the estimation. Categorization and examples of successfully used factors to estimate the failure rate is useful for anyone choosing and creating new models.

The task of finding the failure rate for different power system components in different circumstances has been a topic of research for many years. An early literature study is [1], where hundreds of failure rates from different sources are

This work was sponsored by SweGRIDS. presented divided on component type. The majority of the failure rates are expressed as average constant values for components at different voltage levels, and some results include the age of components. In IEEE Gold book [2] many reported failure rates and references to surveys can be found, and the values presented are on average constant level, with no inclusion of other failure rate explanatory factors than component type. In [3], a survey was made discussing different statistical techniques for estimating time-to-failure distribution with limited data. In [4], the authors present the result from a literature search on failure rates for distribution system components. The presented failure rates are all average rates, with component type as the only explaining variable. None of the above studies have focused on which factors that can be used to express the failure rate. In [5] the advantages and disadvantages of using different levels of accuracy in estimating the failure rates are discussed. No review of presented papers has been found, where the main focus is which explaining factors for the failure rate that have been used in applied case studies. A review of presented work, where different explaining factors for the failure rate in different circumstances are included, could therefore be a valuable contribution to the state of the art.

In this paper, a review of papers presenting results from real data on failure rates for power system components with different explaining variables is presented. To be able to categorize the reviewed papers, a section with a proposed categorization scheme for factors affecting the failure rates is included. The statistical method to estimate the failure rates in the reviewed papers is also noted, and the result of the review is summarized in a table. The intended use for this paper is to exemplify and categorize different possible failure rate factors that can be include in a failure rate model, where all the factors presented is previously and successfully used in others' research.

\section{CATEGORIZATION OF FAILURE RATE FACTORS}

The reliability of a power system network depends on many different things, for example component failure rates, network topology, maintenance, population condition distribution, and operating mode. The theory of evaluating the reliability of power systems is thoroughly presented in [6]. A key input for analyzing the reliability of the network is the components' failure rates, expressed as the expected number of failures for a 
component per unit time, usually failures per year [2]. Although the failure rate is expressed as an average value, it can be seen as a non-constant function of a number of factors, or explaining variables. Other common terms that have the same meaning as factor in this paper are: explanatory variable, independent variable, predictor and covariate. In this view of the failure rate and its dependency, for any given moment, and with perfect information, the failure rate of a single component will be given a value, which is true for that particular moment. This value can be used in reliability evaluation of the power system. In section II.B the proposed classification is described as classes of failure rate factors. Before that, section II.A discusses the difference between end-of-life failures and repairable failures, as well as the difference and usage of failure modes and failure factors.

\section{A. Failure Severity, Modes and Factors}

In this paper no distinction is made between different severities of failures. A failure that is restored after just a few minutes and a failure that makes the component unrepairable are both simply called "a failure". In [2] a failure is defined: "The termination of the ability of a component or system to perform a required function", which hence is adopted in this paper. Depending on the situation, it can be important to understand what type of failures that should be analyzed. Is it the rate of transient failures, causing minor disturbances, or is it the rate of major failures, causing the end-of-life of components, that is interesting, is a question to have in mind before starting an analysis. In the reviewed papers in this paper, examples of both variants are seen.

One way to analyze failures in the power system is to explore the causes of failures, the failure modes, in failure reports, which is called failure mode analysis [6]. The total failure rate for a component can be seen as a sum over all failure rates for the different failure modes. In Sweden all distribution network operators reports all failures leading to more than 3 minutes interruption for any customer. The reports include the failing component and the failing cause, among other things, and are put together by the national energy agency, and the data are available for researchers. In, for example, [7] a failure mode analysis is made from the data in this database. In this paper the failure mode is not in focus, instead the failure rate factors are. A failure rate factor is, in this paper, seen as an explanatory variable that affect the failure rate. Thus, the failure rate is a dependent variable expressed as a function of the independent variables, the failure factors. When including both the failure modes and the failure factors the failure rate of a component can formally be expressed:

$$
\lambda(\bar{v})=\sum_{i=1}^{n} \lambda_{i}(\bar{v})
$$

where $\lambda(\bar{v})$ is the total failure rate for a component, dependent on the variables in vector $\bar{v}$, and $\lambda_{i}$ is the failure rate for failure mode $i$. The vector $\bar{v}$ of factors can be expressed:

$$
\bar{v}=\left\{v_{1}, v_{2}, \ldots, v_{m}\right\}
$$

a vector of $m$ explaining variables, the factors. With this notation it is clear that a failure rate factor can be an explaining variable for more than one failure mode. For example, age can be an explaining factor for failures because of corrosion in joints of an overhead line system, as well as an explaining factor for failures because of a broken pole. Typically, an analysis is made for each failure mode separately, with just one or a few factors.

\section{B. Categorization}

In this section a general categorization of possible failure rate factors is proposed. To date, there exists no consistent obvious categorization of failure factors in the literature, and any specific factor can be argued to go into more than one categorization, depending on situation. In [8], the failure factors are divided into three main categories, namely: intrinsic factors, external factors, and human error factors. In this paper, the categories are chosen based on the type of source of information that can be available, and they are presented here:

\section{1) Component type (CT)}

Different component types have different failure characteristics. A cable has normally negligible probability of failing because of a falling tree, whereas trees are a common failure cause for overhead lines. No work has been found where component type is not a factor; a failure rate is always expressed for a type of component, not just for general power system component. Instead of letting component type be a category of failure rate factors, it could be seen as a requirement to specify which type of component an analysis is made for. For the generality of the categorization, it is however left as a category in this paper. Examples of component types are: overhead lines, cable systems, transformers, and switchgears, possibly divided into different voltage levels, sub types, and other differences.

\section{2) Background information about a component (BI)}

This category includes all information that is known about the component, by looking at its specification and installation information. The failure rate factors in this category are normally lasting, once the component is installed. For example, components of the same type and the same role in the system, but manufactured in different ways or installed differently can have different failure characteristics. Examples of failure rate factors in this category are: manufacturer, model, year of manufacturing, installation company, installation method, and distance between poles.

\section{3) Environment, static (ES)}

The failure rate factors in this category include all information that is known about the location and surroundings, and that are not changing over (shorter interval of) time. For example, an overhead line going over an open field will have a failure rate of zero because of falling trees, whereas an overhead line in the woods are much more vulnerable for that type of failure. Examples of factors in this category are: location, country, area, average climate, animal population, terrain, and type of vegetation. In most studies the ES factors are not included as a variable (since a study is typically made for a specific area), but by comparing different studies, the ES factors can help explaining eventual differences in the results. 


\section{4) Environment, varying (EV)}

In this category, factors that are known from the location at a single moment are included. The difference between the varying and static environment categories are in some cases because of the time horizon of the analysis. For example, the probability of failures because of lightning is of course zero if there is no thunder at the moment, whereas on yearly basis the number of lightning strokes differs between different areas. Thus, the severity of thunder storm, which varies over the year, would go into the varying environment category and the average number of lightning strokes per year for an area would go into the static environment category. Other examples of failure rate factors in this category are: weather, wind speed, snow precipitation, existence of construction projects nearby, and seasonal behavior of animals.

\section{5) Condition $(C)$}

A factor in this category should be measurable for the component. Maybe the most classical condition measure is the age of the component. Naturally, most components cannot operate forever, and it is reasonable to assume that their reluctance against failures gets worse as time goes. Examples of failure rate factors in this category are: age, temperature, oil quality, measure of wear, and corrosion.

\section{6) Operation $(\mathrm{O})$}

In this category factors that describe the operation of the network and component are included. For example, loads near the component limit are likely to imply a stress for the component. Other examples of failure rate factors in this category are: load, load history, switching activities, and disconnections.

\section{7) Preventive actions $(P A)$}

Failure rate factors in this category are those that describe actions that are made to decrease the probability of failures. The aim of preventive maintenance is to improve the component condition, and for many failure causes protective actions can reduce the failure rate. For example, a fence or net could reduce the failure rate because of wild animal impact. Examples of factors in this category are: maintenance actions, installation of protective devices, tree trimming, and replacement of parts.

Clearly, there are many parameters to consider when analyzing the failure rate of components, and practically you cannot include all of them into a failure rate model. Their averages over all or some dimensions are usually used, and most commonly the failure rate is expressed as an average per component type. The most commonly used extensions are to divide the failure rates based on the failure mode and add the factor of age or wear. An exhaustive analysis of all parameters' influence on the failure rate together are likely not possible. Many factors that affect the failure rate are mutual dependent, so the result of one factor can possibly differ in different studies because of different values of other factors.

\section{REVIEW OF PAPERS USING FAILURE RATE FACTORS}

In this section some papers that estimates the failure rate of a component, using explaining factors described in this paper are reviewed. The focus of the review is to describe the factors used and categorize them in one of the categories described in section II.B. Also, the type of estimation method, model used, and analyzed failure modes are mentioned. Each reviewed paper will be described in its own paragraph, and the section will be finished with a table that summarizes the review. In addition, some papers are added to the table without being mentioned specifically in the text.

In [9] a failure rate estimation method is presented, using distribution network failure statistics. In the pre-process step, a component type and failure mode is chosen for further analysis, and the corresponding failures and population are given values for a number of variables, which is used for failure rate estimation using artificial neural networks. The method is applied to failures from the distribution network of greater Teheran, for the period of 2006-2008. Failures that are classified as "momentary", which in their work means failures that do not need any repair, but only disconnections and reconnections, are chosen to be investigated in detail. Variables with a correlation of more than 0.1 where chosen as input variables and the variables in the order of correlation are: Length of the feeder, Inappropriate span length, Inappropriate line sag, Extra MV substation per feeder, Insufficient tree trimming, Improper scheduled PM, normal aging and animal contact. The eight input variables are plugged in the artificial neural network, which contained one hidden layer with a binary sigmoid activation function and non-specified number of neurons, and output variable is the failure rate. Some promising results are presented, where the method predicts the number of failures in 30 test samples quit accurately. The resulting estimated failure rate function is, however, not specified, for re-use or validation for other researchers. In Fig. 1 the used artificial neural network is shown with the eight failure rate factors.

In [10] the Cox proportional hazard model is used for analyzing burn-in failures of medium and high voltage cables and cable joints from a regional electricity company in China. The explanation variables used in the study where: the installing company, the manufacturer, the method of

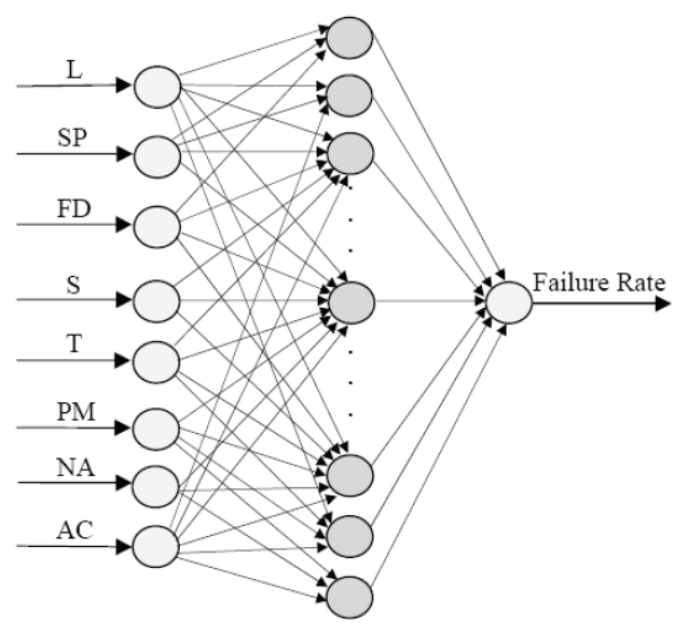

Fig. 1. The architecture of the applied artificial neural network model in [9]. The eight failure rate factors are used as input to one hidden layer and the output is the failure rate. 
installation, and the cable length. All variables where expressed as dummy-variables, stating whether a component belongs to a particular group or not. The number of dummy variables for each explanatory variable was between four and eight, for example the cable length was classified in four groups being: shorter than $0.5 \mathrm{~km}, 0.5-1 \mathrm{~km}, 1-1.5 \mathrm{~km}$, and longer than 1.5 $\mathrm{km}$. Aging failures and failures because of third-party damaged were ignored in the analysis. The result was the parameters for the Cox proportional hazard model, together with $p$-values indicating the significance of correlation. Some useful results were presented, for example a high correlation between the manufacturer and the failure rate of high voltage cable joints was showed, indicating the importance of choosing the right manufacturer.

In [11] a model is presented that computes the failure rate dependency on high wind for overhead lines. In addition, how the restoration time is dependent on weather and time-of-year is also included in the model. A non-homogenous Poisson process is derived, using existing weather statistics, which gives the number of high wind events during the year and when they occur. The failure rate is modelled to be dependent on the squared wind speed, for winds stronger than $21 \mathrm{~m} / \mathrm{s}$, and the wind speed is a function of time, with expected value depending on the time-of-year (month). An interesting result of the analysis was that failures because of high wind contribute to approximately half of the total failures for overhead lines, whereas the annual number of hours with high wind is approximately 9 . The authors show results that indicate that the failure rate is approximately 1000 times higher during high wind than during normal weather conditions. High wind is defined as wind speed above $21 \mathrm{~m} / \mathrm{s}$ and normal weather conditions are everything below that. In Fig. 2 the estimated rate of occurrence of high wind events is shown, which the authors used in their failure rate model.

In [12] the failure rate is estimated as a function of component age and timing of preventive maintenance action, for circuit breakers. The number of failures per age of

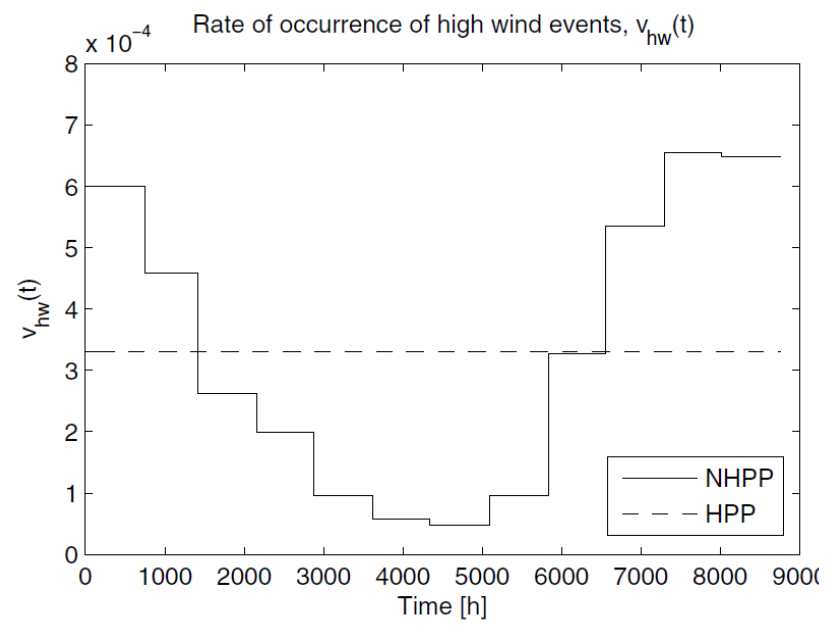

Fig. 2. The estimated rate of occurrence of high wind events in [11], from a non-homogenous Poisson process. The time scale is hours in a year and the steps in graph represents the different months. The dotted line is the average.

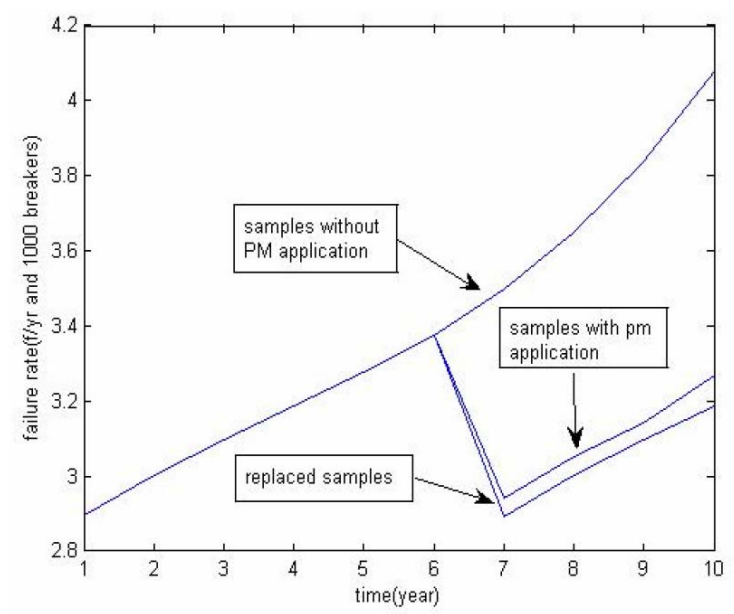

Fig 3. The failure rate as function of age, with or without preventive maintenance, according to the data and model in [12].

components is compared for a sample of 1000 circuit breakers, with and without preventive maintenance at age 7. A 4 degree polynomial is fitted to the number of failures accumulated per year of life. Failure rate is assumed to be 0 for the first year of life and at a constant level for ages above 10 years. The effect of the failure rate factors "preventive maintenance at age 7" and component age is shown in Fig. 3. No sensitivity analysis is presented.

In [13], the effect of age on the failure rate for four main component types is presented. The component types, in the paper, are: overhead lines, cable systems, secondary sub-station (transformers) and switchgear stations (circuit breakers). The authors propose a model from a combination of single-stress models, like the inverse power model and the Arrhenius model. The proposed model is called "electro-thermo-mechanical life model". The failures are divided into ageing failures and random failures and from the applied examples some useful plots are shown. One interesting result is that circuit-breakers seem to be the most sensitive to ageing and overhead lines the

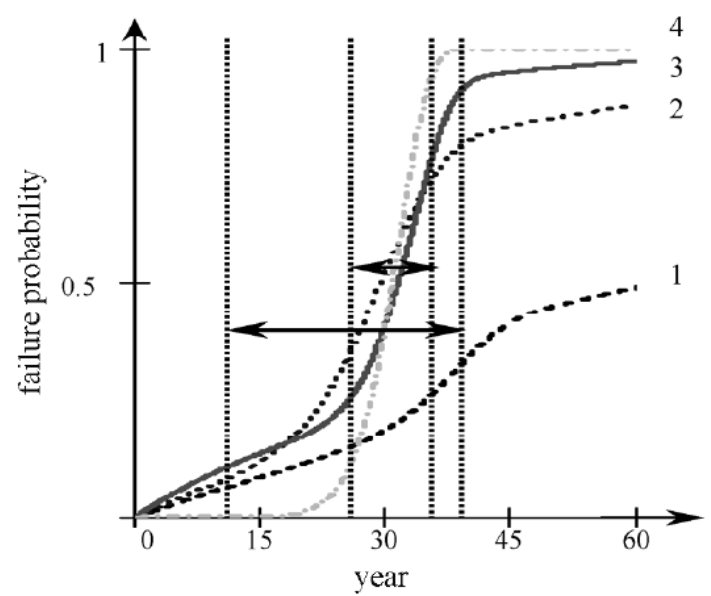

Fig 4. The cumulative distribution functions for 1-OH-line-conductor, 2cable, 3-transformer and 4-cicuit-breaker, according to the model in [13]. 
least, which is indicated in Fig. 4. The paper is giving a review of the age failure factor mechanisms for the four main component types and a lot of references to other works in the field are given.

In [14] a model is presented that describes the relationship between the failure rate and preventive maintenance of XLPEcables, for failures because of water treeing and cables without an extruder layer. The studied preventive maintenance action is to fill water trees with silicon. Failure statistics and laboratory results are analyzed to get the results. The failure rate factors used in the analysis are age and preventive maintenance actions. Failure statistics are fitted to a polynomial function of degree 5 to model the failure rate's dependency on age and a constant value is assumed for ages above 13 years. One of the results is shown in Fig. 5, where the effect of applying the preventive maintenance, described in the paper, is shown.

In [15], four different failure rate models were used to predict the yearly average failure rates for overhead lines, based on the factors: time since tree trimming, the annual average daily minimum and maximum temperature and annual average daily precipitation. Three parametric models and one non-parametric model were used, and the models were compared using a mean-squared error measure. The parametric models were: a single-variable linear model, a single-variable exponential model and a 4-variable linear model, and the parameters were fit using a least squared error approach. The non-parametric model was an artificial neural network model

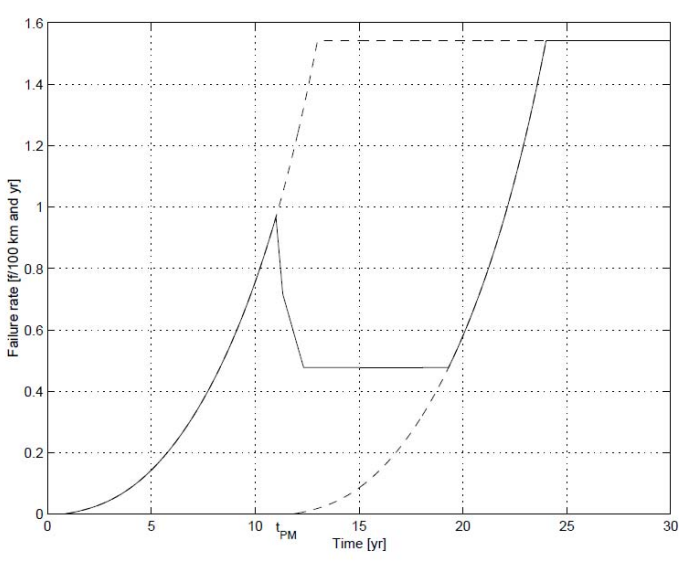

Fig 5. Failure rate of XLPE-cables as a function of age and preventive maintenance at time 11, according the results in [14].

with one hidden layer with 7 neurons. According to the authors' conclusions, the 4-variable linear model performed best in predicting failure rates.

The seven papers that were reviewed in more detail together with a number of more papers are summarized in Table I, with respect of the failure rate factors used, type of model and method, and a note on eventual interesting results.

TABLE I. SUMMARY OF REVIEW

\begin{tabular}{|c|c|c|c|}
\hline Ref & Used failure rate factors & Type of model and method & Interesting result \\
\hline [9] & $\begin{array}{l}\text { CT: OH lines } \\
\text { BI: Length, span length, line sag. } \\
\text { O: Extra substation. } \\
\text { EV: Animal contact } \\
\text { PA: Tree trimming, Scheduled PM } \\
\text { C: Age. }\end{array}$ & Artificial neural network & Good prediction of number of failures in test samples. \\
\hline [10] & $\begin{array}{l}\text { CT: Cables, cable joints } \\
\text { BI: Manufacturer, Installation, length }\end{array}$ & Cox proportional, bath-tub curve & $\begin{array}{l}\text { Big difference on failure rates for different } \\
\text { manufacturers. }\end{array}$ \\
\hline [11] & $\begin{array}{l}\text { CT: OH lines } \\
\text { EV: wind, month }\end{array}$ & Non-homogenous Poisson process & $\begin{array}{l}\text { Failure rate during high wind is } 1000 \text { times the failure } \\
\text { rate during normal conditions. }\end{array}$ \\
\hline [12] & $\begin{array}{l}\text { CT: Breakers } \\
\text { C: Age } \\
\text { PA: Maintenance }\end{array}$ & Polynomial fit & $\begin{array}{l}\text { PM samples and replacement samples show similar } \\
\text { effect on failure rate. }\end{array}$ \\
\hline [13] & $\begin{array}{l}\text { CT: OH lines, cables, transformers, breakers } \\
\text { C: Age }\end{array}$ & $\begin{array}{l}\text { Theoretical electro-thermo-mechanical life } \\
\text { model }\end{array}$ & Circuit-breakers seem most sensitive to ageing. \\
\hline [14] & $\begin{array}{l}\text { CT: XLPE-cables } \\
\text { C: Age } \\
\text { PA: Maintenance }\end{array}$ & Polynomial fit & Promising maintenance action with silicon. \\
\hline [15] & $\begin{array}{l}\text { CT: OH lines } \\
\text { EV: Temperature, precipitation } \\
\text { PA: Tree trimming }\end{array}$ & $\begin{array}{l}\text { Linear fit, exponential fit, Artificial neural } \\
\text { network }\end{array}$ & $\begin{array}{l}\text { All four models were approximately equally good to } \\
\text { predict the failure rate. }\end{array}$ \\
\hline [16] & $\begin{array}{l}\text { EV: Weather, meteorological regions } \\
\text { C: Age }\end{array}$ & Failure rates from other resources, set theory & $\begin{array}{l}\text { Visualize the difference of failure rate when including } \\
\text { different failure rate factors. }\end{array}$ \\
\hline [17] & $\begin{array}{l}\text { CT: } \mathrm{SF}_{6} \text { Breaker } \\
\text { BI: Voltage level } \\
\text { C: Number of operations } \\
\text { O: Operations per year } \\
\text { PA: Preventive maintenance }\end{array}$ & $\begin{array}{l}\text { Weibull distribution fit with censored data, } \\
\text { carefully pre-processing of data used }\end{array}$ & $\begin{array}{l}\text { The number of operations per year has a large impact } \\
\text { of the failure rate. }\end{array}$ \\
\hline [18] & $\begin{array}{l}\text { CT: OH lines } \\
\text { BI: Pole height, conductor separation } \\
\text { EV: Lightning intensity, light storm } \\
\text { O: Number of energize lines } \\
\text { PA: Shielding factor }\end{array}$ & Bootstrapping, Monte Carlo Simulation & $\begin{array}{l}\text { Results show that approximately } 20 \% \text { of the failures } \\
\text { because of lighting flashover are permanent (requires } \\
\text { restoration) and } 80 \% \text { are temporary (cleared by the } \\
\text { operation of a reclosing device). }\end{array}$ \\
\hline
\end{tabular}


[12] M. Fotuhi-Firuzabad and S. Afshar, "Reliability analysis in electrical distribution system considering preventive maintenance applications on circuit breakers," World Academy Sci. Eng.Technology, pp. 741-744, 2009.

\section{Closure}

In this paper seven categories have been proposed to categorize failure rate factors and a review of different research reports using different failure rate factors has been presented. The failure rate factor categories were a useful tool when summarizing the review. The review can be used as a starting point for future work, when the researcher wants ideas and examples of what kind of work that has been done in the topic of estimating failure rates for power system components, using factors to explain differences. From the reviewed papers it can be concluded that by using different explaining factors the accuracy in the estimation of the failure rates, can increase. The different used models in the reviewed papers are showing different strengths; Artificial neural network models seem efficient in using all information available without demanding knowledge about the type of correlation beforehand and the Cox proportional hazard model seem well adapted to show differences in correlation magnitude between different classes of a failure rate factor, to mention a few. The paper contributes to a step towards a better understanding in which failure rate factors that can be interesting to include in a failure rate model and which to exclude. Furthermore, it can inspire and make it easier to choose different methods and factors when estimating the failure rate of power system components in different circumstances, a task that is important in the pursuit of increasing the reliability of the power system.

\section{REFERENCES}

[1] M. Bollen, "Literature search for reliability data of components in electric distribution networks," Eindhoven University of Technology, Faculty of Electrical Engineering 9061442761, 1993.

[2] "IEEE recommended practice for the design of reliable industrial and commercial power systems," IEEE Std 493-2007 (Revision of IEEE Std 493-1997), pp. 1-689, 2007.

[3] C. J. Dent and J. D. Gray, "Component time-to-failure distribution estimation with limited statistical data: A critical survey," in IEEE Power and Energy Society General Meeting, 2011, pp. 1-8.

[4] F. Roos and S. Lindah, "Distribution system component failure rates and repair times-an overview," in NORDAC 2004, Helsinki.

[5] C. J. Wallnerström and L. Bertling, "Risk and reliability assessment for electrical distribution systems and impacts of regulations with examples from sweden," Int. J. Syst. Assurance Eng. and Manage., vol. 1, pp. 87-95, 2010.

[6] R. Billinton and R. N. Allan, Reliability evaluation of power systems, 2 ed. vol. 2: Plenum press New York, 1996.

[7] L. Bertling, R. Eriksson, R. Allan, L.-A. Gustafsson, and M. Åhlén, "Survey of causes of failures based on statistics and practice for improvements of preventive maintenance plans," in 14th Power Systems Computation Conf., 2002.

[8] A. Pahwa, "Effect of environmental factors on failure rate of overhead distribution feeders," in IEEE Power Eng. Society General Meeting, 2004, 2004, pp. 691-692 Vol.1.

[9] E. Akhavan-Rezai, M. R. Haghifam, and A. Fereidunian, "Datadriven reliability modeling, based on data mining in distribution network fault statistics," in IEEE PowerTech, Bucharest, 2009, pp. 1-6.

[10] Z. Tang, C. Zhou, W. Jiang, W. Zhou, X. Jing, J. Yu, et al., "Analysis of significant factors on cable failure using the cox proportional hazard model," IEEE Trans. Power Del., vol. PP, pp. $1-1,2013$.

[11] K. Alvehag and L. Soder, "A stochastic weather dependent reliability model for distribution systems," in Proc. 10th Int. Conf. Probabilistic Methods Applied Power Systems (PMAPS), Rincón, 2008, pp. 1-8.
[13] X. Zhang, E. Gockenbach, V. Wasserberg, and H. Borsi, "Estimation of the lifetime of the electrical components in distribution networks," IEEE Trans. Power Del., vol. 22, pp. 515522, 2007.

[14] L. Bertling, "Reliability-centred maintenance for electric power distribution systems," Ph.D. dissertation, Dept. Elect. Eng., KTH, Stockholm, 2002.

[15] D. T. Radmer, P. A. Kuntz, R. D. Christie, S. S. Venkata, and R. H. Fletcher, "Predicting vegetation-related failure rates for overhead distribution feeders," IEEE Trans. Power Del., vol. 17, pp. 1170-1175, 2002.

[16] F. Yao, Z. H. Zhang, and Y. He, "Grid component outage probability model considering weather and aging factors," $A d v$. Mater. Res., vol. 805, pp. 822-827, 2013.

[17] T. M. Lindquist, L. Bertling, and R. Eriksson, "Circuit breaker failure data and reliability modelling," IET Gener. Transm. Distrib., vol. 2, pp. 813-820, 2008.

[18] N. Balijepalli, S. S. Venkata, C. W. Richter Jr, R. D. Christie, and V. J. Longo, "Distribution system reliability assessment due to lightning storms," IEEE Trans. Power Del., vol. 20, pp. 2153$2159,2005$. 